\title{
Relevant Thinking on Tourism Cultural Derivation and Catalytic Action of Creative Design
}

\author{
Linman Li \\ Chongqing University of Education, Chongqing, 400067, China
}

Keywords: Tourism culture, Creative design, Tourism culture, Catalytic action, Authenticity, Thinking, Cultural creativity.

\begin{abstract}
The issue about how to define connotations of tourism culture specifically has bothered many domestic and foreign scholars for many years. The main idea of this paper is that certain authenticity and independence must be kept all the time so as to realize effective and rapid development of tourism culture. In view of this, this paper focuses on "people-oriented" basic tourism cultural concept, strives to explore a design concept existing in tourism culture, then conducts exploration and analysis on some relevant contents of anthropology, design science and psychology and finally puts forward specifically that the birth of tourism culture has the fundamental nature of design according to the result of discussion.
\end{abstract}

\section{Introduction}

Tourism quality of a scenic spot depends on whether it covers rich tourism culture. Meanwhile, effective development of tourism culture as a specific cultural representation of tourist attractions can improve tourism quality of tourist attractions. In the current stage, the use of culture as a main characteristic of tourist attractions can deeply attract the attention of common tourists to a great extent. In both domestic long-distance and short-distance travel and overseas travel, a tourist souvenir will not have great sales space or any special meaning without its own distinctive culture of tourism[1].Most cultural concepts of scenic spots in whichever place come from "regional culture". Cultural concepts in each place cover their own unique charm. We can call these cultural concepts with different characteristics as aboriginal culture. However, the cultural nature of resource "manufacturing" alone obviously can not present core properties of tourism culture perfectly. Therefore, this paper focuses on discussion and analysis with the primary nature of tourism culture and relevant design for the birth of tourism culture as entry point.

\section{Origin of tourism cultural concepts}

Tourism culture is perhaps not strange to us. However, we must interpret it again in order to have thorough understandings. With a history of several decades and time accumulation, the development of tourism culture has gradually established a comprehensive research system at home and abroad and a lot of research achievements have been made. Among achievements of many tourism cultural researches in China, key contents in Theoretical Perspective on Tourism Culture and Its Relevant Scope and Statement written by Xie Yanjun have specifically pointed out and strictly judged over thirty teaching materials and works about "tourism culture" published in China. The discipline "tourism culture" studied by the academic world hard and carefully has always fluctuated within the scope of "cultural tourism resources" from beginning to end. This paper has caused great repercussions in the academic world once published and produced great conflicts with research achievements of tourism culture made previously. This paper has totally repudiated research achievements of tourism culture made previously in China in some sense. However, critical theories of this paper are not out of thin air to some extent and contents described in the paper have certain 
theoretical foundation from the perspective of the author. Yu Guangyuan, a famous Chinese economist, has ever said, "Tourist industry is not only an economic cause, but also a cultural cause. Tourism is not only an economic life, but also a cultural life." Tourism is not a simple pronoun in literal expression obviously. It implies rich culture. However, some researchers believe that cultural tourism is actually a complex integrating tourism cultural characteristics comprehensively. Tourism culture is often regarded as an attraction for tourists, thus making cultural tourism resources and products a carrier of tourism culture and meanwhile forming a situation that cultural tourism has transformed into tourism culture. Such wrong concept has great and wide influence. The most serious and common adverse influence is that a lot of tourism products are stuck with wrong cultural labels by some fraudulent sellers. The occurrence of such labels has a certain relationship with cultural resources in tourist attractions to a great extent. Meanwhile, some unscrupulous developers fake distinctive culture not belonging to local areas artificially in order to get great economic benefits. Based on basic facts, such wrong tourism culture can not make tourists traveling in scenic spots have cultural and ideological resonance with tourism behavior. Tourists might consider such practice unintelligible. In addition, there is another common understanding of tourism culture, i.e. "The greatest positive meaning of tourism cultural derivation is cultural exchange and communication. Whichever endogenous and externalized forms that can specifically show the core content, i.e. exchange, can be called as tourism culture."[2] Such wrong interpretations of tourism culture only pay attention to put excessive emphasis on cultural fusion but never see beautiful natural sceneries, characteristic buildings and unique cultural customs and folk customs fundamentally and meanwhile do not regard factors above as a catalyst of tourism culture. Therefore, such wrong interpretations of tourism culture have serious deficiencies and have not completely formed a comprehensive system. However, with respect to most research achievements in China, foreign research achievements of tourism culture attach more importance to the exploration on typical cases and specific statements in terms of the interpretation of tourism culture. Most research achievements of tourism culture made do not aim at defining a certain tourism culture; instead, they present some peculiar phenomena produced in the process of tourism specifically. Among these research achievements of tourism culture, famous British research scholar Boniface raised many questions specifically while talking about tourism culture: Can the derivation of tourism culture exist as a whole? Are functions of tourism culture relatively fixed or variable? Does tourism culture bring more benefits or harms in the development path of tourist industry with respect to its position in the current stage? Tourism culture can be understood as a cultural industry. Meanwhile, research achievements of its development should be fully utilized as tourist culture and researches can be conducted after its quantification. For example, some comments of Nco on tourism cultural form for the interpretation of "tourist art" include the accommodation between theme and design can well correspond to interest and expectations arising in tourism; specific standardization of commercial products of tourism; from complication of artistic work to simplification; minimization and maximization of tourism in the journey; elimination of traditional materials and emergence of mechanical products; transformation of utility in life into decorations. From our current perspective, tourism culture is only interpreted as "tourist art" rather than interpreted as a whole. Tourism Culture - Transition of Travel and Theory jointly published by Rojek and Urry can interpret tourism culture most perfectly and present tourism culture most comprehensively. Main contents of the book specifically involve the interpretation of the development of unique characteristic culture by tourism itself in terms of ideological collision of people, constant change and update of sceneries and cultural mobility. It has also been greatly influenced by the concept "passive tourism". Main contents of the book include detailed descriptions on the development of tourism culture by cultural tourism under many conditions according to repercussions produced by the culture of tourism. Cultural tourism can not only produce catalytic action, but also have restrictive functions. In some sense, it is a widest interpretation of cultural nature derived from tourism products. It can also be regarded as re-establishment of another new definition for tourism experience. However, from the point of view of the author, the derivation of tourism culture should be a cultural phenomenon of tourists from different places and existing natural landscape occurring in tourism activities after ideological collision of people. Such cultural 
phenomenon should regard "people-oriented" as the most basic concept of its development and vary with feelings of different tourists. The existence of certainty and variability makes tourism culture have a design attribute in its development process. That is to say, main designers of tourist attractions can give effective suggestions on the construction of tourism culture with language designed carefully. In another sense, the use of design means can further promote the emergence of tourism culture. It's worth paying attention to how designers hide their design language properly so as to minimize the influence on feelings of tourists. Meanwhile, such means will act as a catalyst for the derivation of tourism culture. To solve these problems, the author will make explorations according to relevant knowledge of anthropology and psychology.

\section{Memory and history in tourism culture}

Authority had and has very high degree of convincing among the masses in China. In the field of culture, some authoritative information and thoughts can often gain the trust of the public easily. For example, Travels of Xu Xiake is a book created by the author after his personal travel around China. Meanings covered by the book are very extensive. It not only has made great contributions to geology, but also is a rare travel book about Chinese landscape resources [3].Most tourist attractions in China involve culture marks left by travels of Xu Xiake.Common pattern of manifestation of such culture marks is mainly the statue of Xu Xiake or brochure. Such direct way of representation of authority figures greatly hinders the derivation of modern tourism culture. The presentation of written records about travels of $\mathrm{Xu}$ Xiake to tourists in the form of drawing or poetry will produce two different results: first, personalized tourist emotion corresponding to aesthetic requirements of modern people; second, emotions similar to travel feelings of great men. Tourist emotion corresponding to the thought of modern people can promote cultural changes of tourist attractions to a certain extent. When tourists find their own travel feelings similar to those of great men in historical marks left in the process of travel, they will produce a sense of personal identification and honor spontaneously. This can further promote rapid and effective development of tourism culture, but also present the internal logic of historical inheritance of tourism culture specifically. The two thoughts collide and combine with each other, thus making tourism culture more diversified and comprehensive.

\section{Nature and humanity in tourism culture}

Among multiple attributes of tourism culture, natural scenery has natural cultural attribute. Such cultural attribute is derived from natural scenery itself rather than created artificially. The development of tourist industry in the current stage has economic interests more or less. Due to great economic benefits, the natural cultural attribute of most natural sceneries has been modified artificially. The occurrence of such phenomenon makes most such tourist attractions in China have almost the same development form and specification. Famous British environmental designer McHarg mentioned in Combination of Design with Nature that natural character was more important for the development of tourism culture compared to the existence of human. However, such natural cultural attributes become fewer and fewer due to excessive damage of natural cultural attributes of natural scenery by human. We should respect and cherish gifts given to human beings by nature so that tourism culture can realize long-term development.

\section{Integration of "authenticity" in tourism culture}

To realize long-term development of tourism culture, main relevant principals of scenic spots should rectify some negative phenomena in tourism culture so that characteristic culture in tourist attractions can be packaged and oriented deeply and tourism resources can be developed effectively, uniformly and reasonably. The authenticity of tourism culture is very important for preliminary design and planning of tourist attractions. The creation of authenticity of tourism culture is a feeling produced after personal experience of tourists. Another authenticity of tourism culture is that existing 
in the subconsciousness of tourists, which can also be called as potential existence. Such authenticity of tourism culture is aroused by tourists through the implementation of relevant activities. Such behavior is called as the sense of social identity in management. Therefore, implementation must be conducted according to the authenticity of tourism culture in the process of product integration of tourist attractions so as to avoid damaging the independence of local characteristics and present the truth of tourism culture to each tourist. Tourism culture has the existence of multiple discipline thoughts. It is a product derived from the integration of multiple disciplines. Some researchers considered tourism culture imaginary in the past. However, the author believes that tourism culture truly exists and can be "created" through scientific and reasonable researches. We should combine history and nature so as to establish a true and objective environment for the derivation of tourism culture.

\section{References}

[1] Zhao Shuwang. Catalytic Action of Derivation of Tourism Culture and Creative Design, Hundred Schools in Arts, 2015, 0(04):257-258.

[2] Bi Hailong. Study on Development of Tourism Products Based on Development of Tourism Culture Industry, Academic Exchange, 2014, 0(04): 145-148.

[3] Zhou Lulu. Brief Analysis on Connotations, Inheritance and Development Countermeasures of Tourism Culture, Grand Sight, 2015, 0(05): 60.

[4] Yang Jingjing. Exploration on Application of Traditional Culture in Modern Tourism Culture Design - Take Jinli, Chengdu for Example, Youthful Days, 2014, 0(24). 